In der Rubrik "Literatur kompakt" werden wichtige Arbeiten aus der internationalen Fachliteratur referiert.

In the Journal Club recent publications from the international literature are evaluated.

\title{
Verordnung von Adrenalin-Autoinjektoren: Leitlinienlektüre schützt nicht vor Fehlern
}

Die Frage, welches Kind aufgrund seiner Allergieanamnese mit einem Adrenalin-Autoinjektor ausgestattet werden sollte, wird von Pädiatern und Allergologen oft nicht leitliniengemäß beantwortet.

ritischen Ärzten waren jeweils zehn Fälle von allergischen Reaktionen bei Kindern zur Beurteilung vorgelegt worden. Sie sollten angeben, ob sie dem Kind einen Adrenalin-Autoinjektor verschreiben würden und welche Faktoren ihre Entscheidung beeinflussen würden. 54 Kinderallergologen und 27 Pädiater nahmen an der Online-Befragung teil - oft mit unterschiedlichem Ergebnis (Tabelle 1).
Zwar hatten $94 \%$ der Allergologen und $70 \%$ der Pädiater nach eigener Angabe in der Vergangenheit mindestens eine Anaphylaxie-Leitlinie gelesen. Doch selbst in Fällen mit absoluter Indikation für einen Autoinjektor, hätte sich nicht immer eine klare Mehrheit für diese Vorsorgemaßnahme gefunden (Fall 1 und 3). Sogar nach einer Atemwegsreaktion auf Erdnuss hätte ein Arzt keinen Autoinjektor verschrieben und drei Ärzte

\begin{tabular}{|c|c|c|c|}
\hline \multicolumn{4}{|c|}{ Fallabhängige Verschreibung von Adrenalin-Autoinjektoren } \\
\hline Fall & Daten & $\begin{array}{l}\text { Empfehlung der } \\
\text { Europäischen Leitlinie }\end{array}$ & $\begin{array}{l}\text { Verordnung } \\
\text { laut Umfrage }\end{array}$ \\
\hline 1 & w, $10 \mathrm{M}$, Hautreaktion auf Erdnuss-Spuren & Verordnen & $41 \%$ \\
\hline 2 & w, $2 \mathrm{~J}$, Atemwegsreaktion auf Erdnuss & Verordnen & $88 \%$ \\
\hline 3 & w, $7 \mathrm{~J}$, Hautreaktion auf Erdnuss-Spuren & Verordnen & $37 \%$ \\
\hline 4 & $\mathrm{~m}, 10 \mathrm{~J}$, Hautreaktion auf Walnuss, Asthma & Verordnen & $84 \%$ \\
\hline 5 & $\begin{array}{l}\mathrm{m}, 3 \mathrm{~J} \text {, Hautreaktion auf Kuhmilch, virus- } \\
\text { assoziiertes Wheezing }\end{array}$ & Nicht verordnen & $1 \%$ \\
\hline 6 & $\begin{array}{l}m, 3 \mathrm{~J} \text {, Hautreaktion auf Linsen, abgelegener } \\
\text { Wohnort }\end{array}$ & Verordnung erwägen & $12 \%$ \\
\hline 7 & $\mathrm{~m}, 9 \mathrm{~J}$, orales Allergiesyndrom & Nicht verordnen & $4 \%$ \\
\hline 8 & w, $14 \mathrm{~J}$, Hautreaktion auf Muscheln & Nicht verordnen & $4 \%$ \\
\hline 9 & m, 15 J, idiopathische Anaphylaxie & Verordnen & $94 \%$ \\
\hline 10 & $\begin{array}{l}\text { W, } 1 \mathrm{~J} \text {, sensibilisiert gegen Erdnuss, bisher kein } \\
\text { Kontakt }\end{array}$ & Nicht verordnen & $6 \%$ \\
\hline
\end{tabular}

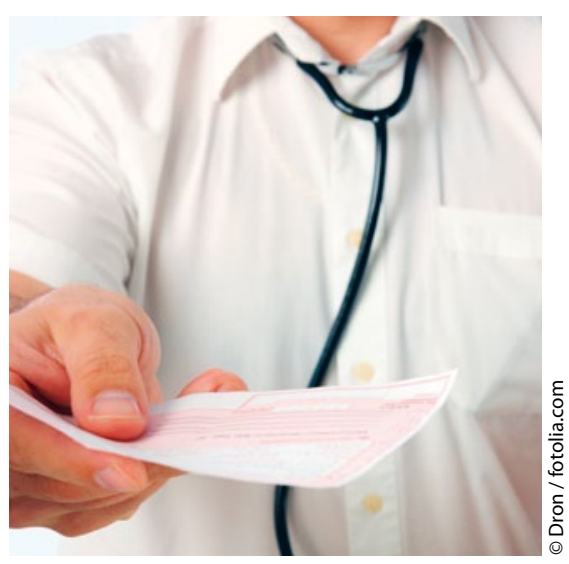

Wann verschreiben Sie einem Kind einen Adrenalin-Autoinjektor?

hätten den Eltern die Wahl überlassen (Fall 2).

Wie sich die Ärzte entschieden, hing ihren Antworten zufolge stark davon ab, ob die Eltern sehr ängstlich waren, eine Nussallergie vorlag oder schon Spuren eines Allergens eine allergische Reaktion ausgelöst hatten. Welcher der beiden Facharztrichtungen die Ärzte angehörten, wirkte sich dagegen mehrheitlich nicht auf das Verordnungsverhalten aus.

Fazit: Trotz Lektüre einer AnaphylaxieLeitlinie besteht bei vielen britischen Allergologen und Pädiatern Ungewissheit, in welchen Fällen ein Kind mit einem Adrenalin-Autoinjektor versorgt werden soll. Inwiefern sich die Ergebnisse der Umfrage auf deutsche Verhätnisse übertragen lassen, ist fraglich.

Dr. Beate Schumacher

Johnson MJ et al. Practices in the prescription of adrenalin autoinjectors. Pediatr Allergy Immunol 2012; 23: 124-7 